\title{
GBEP
}

\section{Aprendizagem e normalidade: reflexões sobre o "não" aprender como parâmetro de exclusão}

Maria Luisa Bissoto

\section{Resumo}

Tem como objetivo discutir a (não) aprendizagem de conceitos acadêmicos e de condutas e hábitos socialmente validados como parâmetro de (a)normalidade e, assim, de exclusão social. A argumentação base é a de que as definições de (a)normalidade, principalmente as que categorizam a deficiência mental, se atêm, primeiramente, a determinadas concepções do que é a mente, do que significa aprender e de quem é o sujeito cognoscente, antes que a atributos portados pelo "anormal" em si. Metodologicamente, a questão da constituição da (a)normalidade da aprendizagem é analisada sob três modelos de cognição: o cognitivismo, o conexionismo e o dinamicismo. Pelos resultados se levanta a reflexão de que, concebendo-se a cognição por referenciais teóricos ligados ao dinamicismo, as delimitações de anormalidade mental, ora existentes, se fragilizam. Como conclusão, longe de negar a existência da deficiência, se assevera que é possível conceber o deficiente como um ser não afastado da ordem, abrindo caminhos para pensar práticas socioeducacionais que lhe permitam constituir-se, de fato, como sujeito.

Palavras-chave: aprendizagem; cognição; deficiência; sujeito cognoscente. 


\section{Abstract \\ Learning and normality: reflections on " non-learning" as exclusion parameter}

The aim of this article is to debate the (non) learning of academic concepts, behaviors and habits socially validated as parameter of (ab)normality, and thus, of social exclusion. The basic claim is that the current definitions of (ab)normality, mainly the ones that categorize the mental deficiency, if abides firstly to definitive conceptions about "what is the mind", "what does it mean to learn" and "who is the cognoscenti being"; before that the attributes carried for the "abnormal person" himself. Methodologically speaking the question of the learning ab(normality) constitution is analyzed in three cognitive models: the cognitivism, the conexionism and the dynamicism. From the results, one reflects the following: when conceiving cognition on dynamicism, the existing theoretical bias of mental abnormality is powerless. Far from the denying the existence of the deficiency as conclusion, one claims that it is possible to conceive the person with special needs not as a being drawn away from the order, opening ways to think socio-educational practices that allows him to be, in fact, a being.

Keywords: learning; cognition; deficiency; cognoscente being.

\section{Introdução}

Nas três últimas décadas, o avanço das pesquisas sobre o cérebro e a cognição humana tem sido marcante. Esse avanço pode ser explicado: a) pelo incremento tecnológico, que vem permitindo investigar, de forma inusitada, o funcionamento do sistema nervoso; b) pelo desenvolvimento e amadurecimento teórico das ciências cognitivas, enquanto campo inter e multidisciplinar de estudos envolvidos com a cognição, seja essa humana, animal ou ligada à vida artificial; e c) ao imbricamento entre as ciências cognitivas e as neurociências.

O entrosamento entre os avanços obtidos na compreensão da cognição e os impactos que esses poderiam ter na esfera da Educação e dos processos de ensino-aprendizagem se mostra, contudo, ainda bastante lento. Neste artigo se defende que esses avanços podem prover importantes suportes para a reflexão filosófica sobre o que é educar, aprender e ensinar e para a elaboração de uma compreensão mais complexa do que seja a deficiência mental.

\section{Norma e deficiência}

A percepção de que ao rótulo de deficiente mental se encontra imanente a idéia de deficientemente humano perturba-co-relação palpável, entretanto, 
e que, embora negada, se encontra subjacente a práticas educacionais e terapêuticas presentes em diferentes ambientes de ação pedagógica e/ou reabilitadora. E dificilmente seria de outra forma: o mental é, genericamente, considerado como o atributo do especificamente humano; é o locus da razão, da inteligência, da abstração, das capacidades mentais superiores, tidas como atributos diferenciadores de humanidade. A categorização de deficiente mental ligada à deficiência, à falha ou fraqueza dessas capacidades vai, portanto, de encontro à negação da humanidade, do que é próprio ao ser humano.

Porém, essas e outras demarcações quanto ao que é considerado "modelo" de humanidade não surgem do nada; são construídas durante o viver, são representações sociais imanentes a outras representações já construídas em uma dada coletividade. O ideal de ser humano, com a definição de características quanto ao que quer que isso signifique, é a anterioridade histórica do futuro deficiente.

A busca por uma outra perspectiva de compreensão da deficiência não pode se restringir, assim, à deficiência mental em si, pois essa é uma categorização transpassada por outras inúmeras categorizações e modos de compreender e interpretar o mundo, constituídas historicamente durante a estruturação dos diversos grupos sociais que compõem uma coletividade mais ampla. No entender deste artigo, tal busca deve se centralizar na análise reflexiva de duas facetas que se encontram entrelaçadas em relação ao deficiente e à deficiência: a) a definição do que é ser normal; e b) a questão do que é aprender.

O que, exatamente, representa estar dentro das normas? O que define o ser normal? Enquanto conceito que só pode ser entendido num contexto comparativo, o que é considerado normal ou anormal se mostra numa relação de inversão e de polaridade. Em Canguilhem (1995, p. 212),

Uma norma se propõe como um modo possível de unificar um diverso, de reabsorver uma diferença, de resolver uma desavença. As normas comparam o real a valores, exprimem discriminações de qualidades de acordo com a oposição polar de um positivo e de um negativo. Uma norma só é possibilidade de referência quando instituída ou escolhida como expressão de preferência e como instrumento de uma vontade de substituir um estado de coisas insatisfatório por um estado de coisas satisfatório.

Os parâmetros delimitadores de deficiência se encontram no mundo vivido, diversamente construídos no interior dos grupos sociais, mas de qualquer forma delineados para diferenciar, pois esta é a função de todo parâmetro: delimitar margens, territórios, espaços de domínio. A busca pela normalidade por parte dos que se encontram excluídos das normas socialmente validadas se revela, desta forma, uma busca fadada ao fracasso, pois a marca de autenticidade de toda normatização é de estar sempre em movimento, de ser sempre questão. Este é seu caráter essencial: acompanhar as transformações do viver, transfigurar-se nestas, permitindo a contínua coesão - e sua contrapartida, a exclusão-grupal.

Expropriado de si por este círculo vicioso, já que as tentativas de adaptação à normalidade subentendem a subordinação à normatividade constituída, que só se processa pelo abrir mão da própria singularidade, pela 
perda do Eu, cabe ao deficiente, com muita pertinência, um rótulo historicamente atribuído aos portadores de debilidades das faculdades mentais: alienado, o que se torna estranho a si próprio, do latim alienare, que pertence a um outro (Hegel, 1992). Enfocar a norma como procura constante pela unificação de atributos, social e, portanto, culturalmente constituída, é deixar caminho aberto para mutações nessa procura, de retraçar normatizações, voltando-as sobre si, reflexivamente.

Isto nos leva ao questionamento do aprender como parâmetro para o ser normal, para o qual uma boa abertura está na citação de Ysseldike et al. (1992, p. 92):

\begin{abstract}
Categorias de educação especial não existem nem em si, nem por si. São construções que ganham significado e vida através da comparação, criteriosa, de performances. Cegueira é o nome pelo qual se assinala a performance visual julgada diferente daquela denominada média ou normal. A menor dotação (intelectual) e o retardamento mental são nomes para assinalar a performance intelectual julgada diferente daquela denominada como média ou normal. A aceitação de critérios para formar uma condição é a pedra angular da definição. Definição é a pedra angular para a existência da condição. Para todo objetivo prático, sem definições não há categorias.
\end{abstract}

Pensando assim, como um ato tão próprio e natural ao ser humano, o aprender, pode se transmutar em instrumento diferenciador e discriminador de possibilidades de vida? A resposta a esta pergunta só pode ser dada quando imbricada a uma outra concepção: a concepção que fazemos quanto ao que seja a realidade e o significado que atribuímos à experiência humana em seu viver. Ou seja: quem é, afinal, o sujeito cognoscente?

A resposta aqui foi buscada no âmbito das chamadas ciências cognitivas, por estas representarem um estudo científico da mente e do conhecimento a partir de uma perspectiva interdisciplinar, envolvendo áreas como a física, a biologia, a psicologia, a sociologia, a filosofia e a inteligência artificial, entre outras.

Enquanto campo teórico amplo, podem ser encontradas, dentro das ciências cognitivas, três correntes básicas de compreensão da cognição: o cognitivismo, o conexionismo e o dinamicismo, sucintamente abordadas a seguir.

\title{
Dos modelos de compreensão da cognição: o cognitivismo e o conexionismo
}

Em suas diferentes abordagens de compreensão da mente, o cognitivismo e o conexionismo retomam, em suas bases, concepções de realidade que têm tradicionalmente direcionado o pensamento filosófico em nossa cultura, o racionalismo, o realismo e o empirismo, retomada que serve de apoio para a análise de dois pontos fundamentais nestas concepções - a idéia de uma realidade onde as coisas (inclusive a mente) existem em si, possuindo propriedades particularmente definidas, e a idéia de que o 
real se configura por meio de nossa interação com a realidade - e suas respectivas implicações na constituição de nossas crenças quanto ao que seja a mente e o ato cognitivo.

Epistemologicamente, como se fundamentam estas concepções?

Com relação à concepção de realidade, o cognitivismo parte de uma posição realista, que entende o mundo físico, do qual a mente faria parte, como existente em si e por si, embora se aproxime também de concepções racionalistas da mente, entendendo esta como um conjunto de habilidades apriorísticas, estruturalmente determinada, que atua promovendo as condições para a apreensão do mundo material exterior. A comunicação entre ambas as instâncias, mental e física, é dada por meio de abstrações que a mente realiza sobre a realidade material, palpável, do mundo físico, e que se processa através da re-presentação: do tornar o objeto sobre o qual incindiu o pensamento, ou, melhor dizendo, sobre o qual o pensamento foi intencionado, novamente presente para mim, através da ordenação formal, portanto física, sintática, dos constituintes funcionais deste objeto. Nessa comunicação entre o mundo físico e a mente, qual é o papel do sujeito cognoscente?

Acompanhando a concepção racionalista da mente, para o cognitivismo a experiência sensorial não é a base para o conhecimento: a razão, quando propriamente usada, pode prover verdadeiras crenças ou princípios, delineando as reais essências das idéias. A experiência, o contato do sujeito com o mundo, entraria como provedora de dados objetivos, extraídos de uma realidade verdadeira, "alimentando" o uso racional ou a descoberta desta verdade (Schwartz, 1999).

Concepção de sujeito cognoscente racional e realista, que estabelece uma relação de apropriação funcionalista entre o sujeito e o mundo - apropriação, porque a "descoberta da verdade" existente no real se configura como uma relação de posse do sujeito com relação a este; e funcionalista, porque concebida como relação entre um mundo físico detentor de dados que retém sua verdade e uma mente detentora de capacidades que a habilitam a extrair esta verdade -, esta relação acaba sendo de causa/efeito: a todo ato cognitivo bem executado deverá corresponder a obtenção da verdade!

Implícita a esta concepção, podem ser encontradas as seguintes considerações: a) a questão da hierarquização (evolucionária) da cognição; e b) a questão da representação mental.

Segundo Ramsey (1999), esta vertente realista e racionalista adotada pelo cognitivismo tem sido popularmente apreciada, entre outras razões, porque é difícil explicar como as capacidades cognitivas são adquiridas sem assumir que há alguma forma de conhecimento prévio inerente ao sistema mental. Ainda: a idéia de que a aprendizagem ocorre quando novos conceitos, mais complexos, são construídos sobre conceitos mais primevos reforça esta concepção, pois sugere que devemos, primeiramente, ter um estoque de conceitos básicos, os quais, por hipótese, não são aprendidos. Imbricada nesta concepção está a idéia de que capacidades cognitivas localizadas em um certo nível cerebral são, tipicamente, mais simples e menos 
numerosas do que as que estão posicionadas em um nível mais alto, com os níveis mais baixos especificando instruções para a performance de ações que não requeiram inteligência. Temos, então, de acordo com este enfoque, capacidades mentais "inferiores" e "superiores", numa escala crescente bottom-up, proporcional ao grau de habilidade cognitiva desempenhada pelo sujeito, sendo tanto superior quanto maior for a capacidade de abstração e de representação simbólica da mente.

O cognitivismo, numa visão compartilhada com outras correntes de pesquisa nas ciências cognitivas, aborda a relação entre evolução e cognição enfocando a mente como um conjunto de algorítmicos darwinianos, ou seja, como uma estrutura "desenhada" anatômica e fisiologicamente, em níveis crescentes de complexidade, pelo processo de seleção natural, como forma de capacitar nossos primitivos ancestrais para a resolução de problemas encontrados em seu viver no ambiente físico, perpetuando-se, pela hereditariedade, as modificações que ofereceram condições otimamente efetivas de sobrevivência... estrutura gradualmente modificada, que teria provido a base para o desenvolvimento de habilidades mentais progressivamente superiores, a todo este processo estando imanente a aquisição do conhecimento, elemento de aprimoramento destas habilidades e, através deste aprimoramento, ele próprio, complexificado.

Concepções que nos parecem tão familiares, tão cientificamente propagadas, que acabam nos dando a segurança da verdade, de que é assim.

Entretanto, de acordo com Varela (1996), este modelo tem sido questionado, exatamente, por um de seus dogmas centrais: a noção de adaptação. Segundo este autor, o conceito de adaptação proposto pela teoria evolucionária - principalmente a neo-darwiniana - se encontra ligado ao de abundância, no sentido de sucesso. Se o problema básico da evolução consiste em achar estratégias hereditárias, conjuntos de genes inter-relacionados que serão mais capazes de contribuir para a sobrevivência do indivíduo e, portanto, para uma subseqüente reprodução otimamente diferenciada, quando isto ocorre a evolução foi bem-sucedida, resultando em uma superioridade genética individual de um sujeito que, teoricamente, se adaptará melhor - terá mais sucesso em sobreviver, maior abundância de possibilidades de vida - em sua interação junto ao meio, tendo como resultante uma prole hereditariamente aperfeiçoada. Ainda uma vez, o deficiente "nega" a humanidade...

Paralela à idéia de que a evolução humana se deu de forma gradual e geneticamente selecionada, isto é, tendendo à perfeição, está a idéia, presente em muitas teorias, no âmbito das ciências cognitivas e fora delas, de que o desenvolvimento humano segue o mesmo caminho: da infância mais precoce à idade adulta, deve haver um aprimoramento das capacidades cognitivas, aprimoramento também algorítmico, com fases menos complexas se antecedendo e fundamentando o desenvolvimento de capacidades cognitivas mais complexas. Novamente a idéia de progressão, de que o caminho natural para o desenvolvimento humano é o aperfeiçoamento de capacidades, que potencializará a adaptação - a correspondência otimizada - mundo/ sujeito. E se o sujeito não consegue essa correspondência otimizada com o mundo? 
Voltando à questão da representação, a principal pressuposição é de que ela preserva a estrutura da realidade existente, e o faz por meio de estados mentais intencionais: estados mentais que têm um conteúdo, que são acerca de certos objetos, e assim devem aparecer na representação mental.

Para o cognitivismo, os processos computacionais pelos quais a representação se efetua não podem ser, por nós, percebidos: como ocorrem de forma encapsulada, dentro de módulos de domínio específico e inatos, encarregados de uma determinada função - módulos de linguagem, de reconhecimento visual... -, são insensíveis à autopercepção do sujeito, ignoramos as regras que governam a estes, mesmo por que a percepção de tais processos tornar-nos-ia mais lentos, menos funcionais. Desta forma, o domínio da cognição é determinado, basicamente, por estados mentais dos quais não somos conscientes: para os cognitivistas, cognição e intencionalidade (representação) são um par inseparável, não cognição e consciência (Varela, 1996).

Concepções que nos levam a conceber o aprender como o armazenamento progressivamente complexo de conhecimento extraído/ modelado das coisas; ação neutra e aistórica de inputs a alimentarem a programação cerebral. Volição, desejo, prazer, aversão, retrospecto de vivências, nada conta nessa concepção de realidade/mente objetiva, que prescinde de um doador de sentido, de um intérprete, para ser conhecida, conhecimento que só compreendido sob esta forma pode ser abstraído, analisado, modelado, retransmitido.

Em fins da década de 1970 e na década de 1980 ganhou força uma outra corrente das ciências cognitivas, que, contrariamente ao cognitivismo - e originada das limitações desse modelo para explicar a plasticidade e complexidade das funções mentais, crescentemente demonstradas pelos novos processos então surgidos de investigação do sistema nervoso -, concebe os componentes cerebrais interconectados, operando em paralelo, por meio de inúmeros subsistemas de redes. Por considerar que o sistema cerebral funcionaria como um conjunto complexo interconectado de forma não linear/serial, essa nova corrente das ciências cognitivas recebeu o nome de conexionismo.

Ao conceber o ato cognitivo como propriedade emergente de um sistema auto-organizativo, o conexionismo resgata o papel da experiência do sujeito cognoscente no mundo vivido: conhecer é a capacidade de sintetizar novas configurações neuronais de acordo com as experiências que o sujeito estabelece em sua interação com o ambiente (interno e externo), enfoque que aproxima, epistemologicamente, o conexionismo do empirismo.

O empirismo se apresenta como corrente teórica que concebe que todo nosso conhecimento advém da experiência, da interação mundo/sujeito, interação estabelecida, primordialmente, pela via sensorial. De acordo com Schwartz (1999), para o empirismo "nossos sentidos não somente suprem a evidência avaliável para justificar nossas crenças, mas são as raízes, os fundamentos dos conceitos que constituem estes pensamentos". Tendo este argumento como pressuposto central, para o conexionismo o cérebro pode 
ser visto como operando sobre uma base de massivas interconexões entre os neurônios, conexões que se dão de forma distribuída, difusa, estabelecendo redes neuronais que se configuram e reconfiguram de acordo com a ativação nervosa advinda da excitação sensorial decorrente de um ambiente estimulador, ambiente que, desta forma, funciona direcionando o rumo da arquitetura cognitiva que emerge como propriedade das redes neuronais como um todo, esforço do sistema em responder à "perturbação" sensorial recebida.

Como todo conhecimento emana da experiência sensorial, não há verdades a priori, exceto para poucas afirmações que são consideradas analíticas - por exemplo, todo triângulo é constituído por três lados. Entretanto, apesar desta negação de conhecimentos a priori, o enfoque empirista considera que há disposições inatas que influenciam o modo como interagimos com o meio, disposições; todavia, que em nada se assemelham à concepção, mais racionalista, de que nascemos com "idéias".

Temos então, atrelada a estas considerações, uma concepção de realidade (aparentemente) bastante diferente daquela proposta pelo cognitivismo. No conexionismo, embasada pelos dogmas empiristas, a realidade é composição do sujeito, não é estática, fixa, mas dinâmica, mutável, estabelecida em um fluxo interacional com um sujeito que também muda, cujo quadro cognitivo se altera no momento mesmo da interação. As idéias, nesta concepção, são a posteriori, isto é, são, em última instância, decorrentes da interação causal mundo/sujeito, idéias que se associam, partindo das mais simples, as sensações sensoriais, constituindo pensamentos - percepções internas de estados psíquicos, reflexões, que derivam significado das experiências e da variação de estímulos necessária para inspirar o comportamento do sujeito. O papel da razão, neste quadro, segundo Schwartz (1999), é o de ajudar a organizar e verificar as implicações quanto ao que é captado e conduzido pelos órgãos sensoriais; a lógica podendo contrastar padrões apropriados de raciocínio, mas a razão, por si própria, não assegurando a base para o conhecimento, para a compreensão do mundo exterior.

Na análise de R. A. Wilson (2005), os empiristas afirmam que não há nada na mente que não se encontre primeiro nos sentidos, havendo então um vasto sentido literal de que as idéias encontradas na mente são complexos que derivam de impressões sensoriais. Isto, por sua vez, sugere que os processos que governam a cognição são, eles próprios, elaborações daqueles que governam a percepção, ou seja, que a cognição e a percepção diferem apenas em grau, não em qualidade. Desta forma, a mente é vista como um sistema de domínio geral, em que as leis que governam as operações mentais são constantemente atravessadas por diferentes tipos e níveis de cognição, sobre a mesma base empírica de constituição do conhecimento.

Concepção que se contrasta à ótica cognitivista, porque, entre ambas as hipóteses, muda a concepção de realidade, de interação mundo/sujeito, e, por conseguinte, a concepção de sujeito cognoscente: para o conexionismo - e ainda mais radicalmente para as novas linhas desta corrente, denominadas de conexionismo dinâmico - este sujeito não é o que reproduz, mentalmente, uma realidade já posta; é o que, contrariamente, cria, dá vida a uma 
realidade e o faz por que é, essencialmente, um sistema auto-organizativo, que depende desta interação dinâmica com o ambiente para poder se constituir e para manter sua constituição, pois, tal como a realidade, também não se encontra pronto, fixo - se constrói. E se constrói pela experiência no mundo vivido.

Justamente pela concepção de que o sistema cognitivo funciona como uma rede auto-organizadora, encontramos, na perspectiva conexionista, uma série de quesitos que a diferenciam da abordagem cognitivista mais tradicional. Acompanhando a análise de B. Smith (1998, p. 3), para o conexionismo:

a) as interconexões neuronais, "trilhos" para o ato cognitivo, são mais paralelas do que seriais, operando sobre atributos semânticos;

b) as interpretações de tais atributos são baseadas mais no uso ou na experiência, do que na pura denotação ou descrição: são menos conceituais ou simbólicas;

c) são mais baseadas na ação e engajamento no ambiente do que no racionalismo dedutivo, contrastando habilidades cooperativas com esquemas de dedução e

d) ocorrem em tempo real, não há estrutura cíclica de sinto-pensoatuo, é continuamente co-evolutiva à experiência.

Entretanto, em que pesem as diferenças, há, entre ambas as correntes, pontos em comum, acerca dos quais são aqui estabelecidas algumas problematizações. As duas hipóteses, de forma coerente às bases epistemológicas em que se fundamentam, são mentalistas: o locus da cognição, da consciência, da razão, continua sendo, por excelência, a mente. Também concordam em que a "moeda" do mental são idéias, e, para a maioria dos empiristas e conexionistas, idéias não são menos representacionais do que para os racionalistas e cognitivistas (Schwartz, 1999).

Se para o cognitivismo, entretanto, representação é espelhamento de uma realidade existente, concreta e independente do sujeito, para a maioria das correntes conexionistas, o conhecimento, apesar de indissociável da atividade perceptiva do sujeito no mundo vivido, ainda se encontra preso à idéia de que as percepções elaboradas estão associadas e em correspondência a atributos primários presentes no mundo físico exterior - aparente paradoxo entre a criação do real e a manutenção de uma correspondência entre representação mental/realidade, que pode ser justificado pelo modelo empirista encontrado em Locke, e que foi acompanhado de perto pela perspectiva conexionista.

Implicada na concepção de que a mente, ao nascimento, é tabula rasaou, em uma linguagem mais cibernética, uma estrutura formada por redes neuronais ainda não expostas a nenhuma forma de ordenamento quanto a uma arquitetura cognitiva - que vai sendo "preenchida" por estímulos sensoriais já existentes, de certa forma, no mundo físico, desencadeando interconexões neuronais e constituindo a base para o surgimento de pensamentos mais complexos, está a concepção de que, em nossa interação com 
o meio, é este quem aciona o rumo de nosso desenvolvimento, em particular, nosso desenvolvimento cognitivo.

Concepção que mantém presente, apesar da mudança de enfoque, a idéia de que estamos em constante adaptação a um mundo que, agora, nos governa pelo plano da experiência - experiência que se acumula, que complexifica as redes neuronais, as associações de percepções, o pensamento...

Aprender é acumular experiências? É complexidade de pensamento? É "amadurecer"?

Mas há ainda outra consideração quanto a um aspecto comum ao cognitivismo e ao conexionismo: a concepção de que nossos órgãos sensoriais são as portas de entrada para o conhecer, frestas através das quais somos penetrados pelo mundo. Compreendidos como captadores de informações, sedimentam, segundo Assmann (1998, p. 37), a concepção de um perene dualismo entre mundo/sujeito:

A idéia de que os sentidos funcionam como janelas do conhecimento é tão corrente que o próprio conceito de conhecimento começou a ser visto como rachado em dois subsistemas: o indivíduo e o meio, o receptor e o emissor, o aluno e o professor, etc. Daí para a frente, ficou difícil tornar plausível que, na verdade, a primeira consideração acerca do processo de aprendizagem sempre deveria ser a de que existe um sistema unificado organismo-e-entorno e que isso não vale apenas para reações vitais primárias no plano biofísico, mas se aplica igualmente ao mundo das linguagens.

Idéia que pode remeter à concepção de um sujeito cognoscente fragmentado em sua interação com seu entorno, ora recebendo e transmitindo informações por canais visuais, ora por canais táteis ou auditivos... canais que, quanto melhor funcionarem, melhor permitirão a captação e o subseqüente processamento das informações, potencializando o ato cognitivo, o que remete à importância que é atribuída, por várias técnicas pedagógicas e terapêuticas, quanto à estimulação que visa o aprimoramento sensorial dos sensores -, aperfeiçoando a discriminação auditiva, visual, tátil, olfativa e gustativa... (estas duas últimas, aliás, geralmente relegadas a segundo plano, provavelmente pelas poucas associações que lhes são atribuídas com relação ao aprender acadêmico).

Como principal ponto diferencial entre ambas as correntes, pode-se afirmar que na vertente conexionista há a emergência de novos estados no interior do sistema, a partir de inputs iniciais. Esses novos estados não seriam, porém, como defendido pela vertente cognitivista mais clássica, determinados pelos inputs que adentram o sistema; antes, significa que novos padrões de organização se formam provocados pela entrada de informações. Novas e imprevisíveis estruturas organizativas surgem como esforço do sistema em responder, como um todo, às perturbações suscitadas por um entorno estimulador.

Amparada pelos dogmas empiristas, no conexionismo a realidade não é percebida como estática, fixa, mas dinâmica, estabelecida em um fluxo interacional com um sujeito que também muda. Entretanto, a maioria das 
correntes conexionistas, embasadas no modelo empirista como concebido por Locke (1632-1704), não se desprende da correspondência entre percepções e atributos primários encontrados no mundo físico exterior: há, ainda, uma concepção de mundo posto antes dos sentidos.

Ora, se há "verdade", conhecimento, informação, posta nas coisas e não consigo percebê-las/conhecê-las como tais, a razão falhou em sua verdade: a apropriação do real. Essa falha "descredencia" o sujeito cognoscente quanto ao domínio do mundo. Há uma delimitação quanto à natureza (ou, do que é próprio à) daquele que conhece, pois já há um pressuposto do tipo de mundo possível de ser constituído e com o qual deve haver consonância de reconhecimento, sob pena de não ser validado ou de o ser como ilusão, delírio, erro de percepção, posição que encontra respaldo em Merleau-Ponty (1996, p. 56):

\begin{abstract}
O empirismo não vê que precisamos saber o que procuramos, sem o que, não o procuraríamos, e o intelectualismo não vê que precisamos ignorar o que procuramos, sem o que, novamente, não o procuraríamos. Ambos concordam no fato de que nem um nem outro compreendem a consciência ocupada em apreender, não notam essa ignorância circunscrita, essa intenção ainda "vazia", mas já determinada, que é a própria atenção. Quer a atenção obtenha aquilo que procura por um milagre renovado, quer o possua previamente, nos dois casos a constituição do objeto passou em silêncio. Seja ele uma soma de qualidades ou um sistema de relações, desde que existe é preciso que seja puro, transparente, impessoal, e não imperfeito, verdade para um momento de minha vida e de meu saber, tal como emerge à consciência. [...] as duas doutrinas têm portanto em comum essa idéia de que a atenção não cria nada, já que um mundo de impressões em si ou um universo de pensamento determinante estão igualmente subtraídos à ação do espírito.
\end{abstract}

\title{
O aprender como processo organizativo vital
}

As várias formas de conceber a cognição humana parecem sempre apontar para a idéia de erro quando o sujeito cognoscente demonstra não conseguir estabelecer uma co-relação social e culturalmente tida como adequada entre o uso da razão, a percepção sensorial e a apreensão do "conhecimento" (da verdade) existente no mundo exterior. Sobre essa base de falha/erro/verdade é que se estabelece a delimitação do deficiente como tal. Considera-se aqui que uma outra concepção de cognição, distante desse posicionamento, possa colaborar para uma outra concepção quanto à deficiência, ampliando os horizontes de compreensão desta. O modelo de cognição proposto abaixo considera essa como um processo (auto)organizativo vital, corporificado e situado.

Por auto-organização se entende, de acordo com a definição de M. Debrun (1996, p. 13):

Há auto-organização cada vez que, a partir de um encontro entre elementos realmente (e não analiticamente) distintos, desenvolve-se uma interação sem supervisor (ou sem supervisor onipotente) interação essa que leva eventualmente à constituição de uma "forma" ou à reestruturação, por "complexificação", de uma forma já existente. 
Para compreender a cognição como processo vital, duas concepções anteriores são especialmente importantes: a) conceber os seres vivos como sistemas abertos, dependentes de um fluxo contínuo de energia e de informações, recolhidas do imbricamento ser vivo/seres vivos/entorno e a capacidade destes sistemas em fazer emergir novas formas de comportamento e de organização interna, pela interação não linear e paralela de seus próprios recursos e dos recursos advindos do imbricamento relacional com outros sistemas, mantendo assim sua integridade; e b) todo conhecimento só pode ser compreendido enquanto limitado e aproximado, circunscrito à corporeidade daquele que conhece e dependente de um contexto - a vida, enquanto teia dinâmica de relações, não pode ser completa e definitivamente conhecida.

Estas são concepções que norteiam, epistemologicamente, teorias contemporâneas das ciências cognitivas: a de cognição corporificada e a de cognição dinâmica, ou dinamicismo, aqui representadas pelas posições defendidas respectivamente por Francisco Varela (1996) e por Tim van Gelder (1995, 1998).

Na argumentação de Varela (1996), a idéia de cognição corporificada e emergente permite transpor a polaridade epistemológica presente na tradição filosófica ocidental, que oscila entre posições objetivistas e subjetivistas, essencialmente baseadas na suposição de que temos um eu (self) já existente, acabado, que, no caso do objetivismo, deve voltar-se para abstrair padrões de "verdade" presentes numa realidade exterior, e que, no caso do subjetivismo, deve, em última análise, originar os contornos do real. Contrariamente, na argumentação de Varela (1996), o sujeito cognoscente, em seu agir no mundo vivido, vai criando o seu eu (self) em compasso com sua estrutura biológica e sua ontogenia, tramando seu desenvolvimento pessoal e possibilitando transformações no modo de encadeamento ser-entorno.

Sob o termo de hipótese dinâmica, ou dinamicismo, se agrupam várias linhas de pesquisa, originalmente de base conexionista, que afirmam que a cognição pode ser melhor explanada como propriedade emergente de um sistema dinâmico e não-linear, que se auto-organiza de acordo com flutuações na estabilidade percebida, do que como um "coordenador mestre", que atua enviando instruções simbólicas para o restante do sistema. Estas pesquisas se diversificam em campos tão distintos como o estudo do controle motor, do desenvolvimento psicológico, da psicologia cognitiva e social, da robótica e da inteligência artificial, entre outros, e poderiam ter, como síntese de suas propostas, o slogan "sistemas cognitivos são sistemas dinâmicos".

São concepções que se diferenciam com relação às outras epistemologias aqui abordadas por argumentarem que a cognição:

a) não é centrada no sistema nervoso, mas é corporificada, pois depende da experiência (e não somente da experimentação) do sujeito cognoscente no mundo vivido,

b) não é baseada na representação de uma realidade pré-determinada. Há um mundo material, porém não previamente configurado. O sujeito cognoscente, em sua interação com o entorno, traz à 
tona um mundo, fruto do esforço auto-organizativo integral do sistema e,

c) é mutuamente transformadora, pois mudam continuamente, durante o processo de conhecer, o agente cognoscente e o entorno, em virtude da ação seletiva e interpretativa do primeiro sobre o segundo.

Nessa compreensão de cognição, toda perturbação percebida pelo organismo em sua interação com o meio e que impulsionará outras formas de relação ser/mundo, ou de aprender a ser em seu entorno, só é possível pela história de vivências deste organismo. A interação sujeito cognoscente-meio é validada pelas escolhas de estímulos efetuadas por esse sujeito, movida pelas necessidades e prazeres de manutenção de sua auto-organização, só podendo ser compreendida como inerente à sua ontogenia. Ação e percepção são inseparáveis na cognição vivida; não há a seriação sinto (experimento, percebo)-penso (represento)-atuo. Argumentação ilustrada pela afirmação de Assmann (1998, p. 111):

É preciso dar-se conta de que a epistemologia tradicional gera uma determinada relação com o mundo e as pessoas e essa relação é de oposição, defensiva ou agressiva. A realidade é vista como um conjunto de objetos captáveis e, portanto, manipuláveis. Conhecer seria, nessa visão, apoderar-se de certa forma das coisas para poder controlá-las. É importante que se entenda este cerne, ética e politicamente agressivo e reacionário, da epistemologia tradicional. Por isso a ruptura com semelhante epistemologia é uma questão ética e política, já que, além de referir-se ao modo de ver o conhecimento, refere-se também à maneira de relacionar-nos com o mundo e as pessoas.

Mudanças de perspectiva em relação à cognição que permitem as seguintes inferências, mormente em relação à deficiência mental:

a) Se enquanto estruturas auto-organizativas ligamo-nos ao entorno de acordo com as especificidades requeridas pela manutenção de nosso viver, questionamos assim o dogma de que há um único caminho para o tornar-se humano, pois, embora havendo um desenvolvimento filogenético, o viver não é obrigado a se enquadrar em etapas prescritivas para poder alcançar um desenvolvimento otimizado, ou o mais próximo possível disto, considerado como próprio à espécie. É argumento para o não conceber a deficiência mental como forma evolucionária atrasada, primitiva ou incompleta;

b) Se a cognição está limitada à apreensão ou "descoberta" dos atributos presentes na materialidade que cerca o sujeito, educar é adaptação do sujeito à realidade, ao mundo, através do domínio deste "conhecimento"? Se isto significa subordinação e o amoldar do sujeito ao meio, não. O conceito defendido aqui é, inversamente, o de adaptabilidade, definido como o acoplar constante sujeito/entorno, resultante de nossa flexibilidade e plasticidade estrutural, diferenciação que apóia o paradigma de educação inclusiva, atualmente defendido, e que ultrapassa, com 
vantagens, o paradigma da pura integração social do deficiente, marcada pelo caráter de adaptação/subordinação deste ao seu entorno social.

c) O sujeito cognoscente está sempre por ser (e já sendo) feito, abrindo continuamente novos horizontes para a constituição do viver. Os limites para o desenvolvimento do ser humano se mostram muito mais socioculturalmente impostos do que determinados pelas condições genéticas que cercam a esse.

d) Se os "dados" que integram a realidade não se encontram nessa, estaticamente disponíveis, só adquirindo significado mediante a interlocução auto-organizativa sujeito/entorno, torna-se difícil defender que aprender é abstração/racionalização sobre atributos postos num mundo exterior ao sujeito. Sem esse parâmetro de entendimento quanto ao que é aprender, como definir quem é o deficiente mental?

e) Se conhecer é interação mente/matéria firmada sobre a necessidade de viver, inseparável do desejo, do prazer, então conhecer é nascer enquanto sujeito (Cordiè, 1996), é constituir-se como ser de desejo, não é armazenar informações ou adaptar-se a estruturas previamente determinadas - envolve um projeto de vida, um horizontes de perspectivas. Novamente, quem é, então, o deficiente mental? Desejo que morre, perspectivas que se fecham quando constituímos o deficiente como ser dominado, processo que se cristaliza, em muito, pela vertente educacional. E terapêutica.

f) Dominação do outro que nos expropria quanto à nossa própria humanidade, pois só domino o outro quando o objetifico, objetificando a mim mesmo como seu semelhante. O que torna mais pesado o viver de todo o entorno social, pela ameaça, percebida e impossível de ser afastada, de que há delimitadores socioculturais que instituem a existência de vidas não reconhecidas como viáveis. Ou plenas.

\section{Considerações finais}

Num retrospecto das posições aqui defendidas, as "dificuldades" encontradas pelas pessoas consideradas como deficientes em seu viver são, principalmente: a) determinadas pela sociedade através de suas leis, normas e instituições e não somente pelas próprias deficiências em si; b) provêm da natureza das situações encontradas pelos indivíduos deficientes no âmbito educacional, nas circunstâncias sociais e das condições de empregabilidade proporcionadas; e c) determinadas pelos grupos sociais, por suas atitudes e provisões de suporte quanto às condições para o viver do deficiente em sociedade.

O conceito de aprender, que mais comumente se encontra ligado à apreensão e elaboração mental "certeira" de um real constituído por atributos delimitadores e definidores de uma essência peculiar, se revela, nessa demarcação social da deficiência, como o parâmetro mestre do que é ser mentalmente falho: deficiente. Se, numa outra concepção de aprender, pudermos conceber a este como processo no qual o sujeito se constitui enquanto ser de desejo, envolvendo um projeto de vida, um horizonte de 
perspectivas, podemos modificar os contornos de constituição cultural da deficiência.

A situação de exclusão do deficiente mental - assim como a de outros grupos sociais que são rotulados como minorias (qualitativamente mais do que quantificadamente) - não se alterará enquanto uma modificação nos mirantes de compreensão e interpretação de mundo não se concretizar. E em relação à exclusão, a sociedade pós-moderna nos coloca grandes desafios... Diante das mudanças no mundo do trabalho, das transformações econômicas advindas da internacionalização do capital e do incremento tecnológico em geral, o número de pessoas catalogadas como "deficientes", o número de excluídos, crescerá. Uma sociedade que parece se caracterizar por uma competitividade crescente, que valoriza a posse e a capacidade de produzir acima de quaisquer outros valores, que, enfim, idolatra um ideal de perfeição produtiva - biológica, intelectual estética, financeira...-, rejeita fortemente a semelhança ameaçadora com o "fraco".

A inclusão social do deficiente, incorporando atitudes de maior dignidade e respeito a ele, só acontecerá, de fato, quando nossa concepção quanto ao que é o mundo vivido e o significado da experiência humana neste mundo, também mudar. O estabelecimento de uma história de interações baseada na aceitação e não na exigência, na distinção entre o ser diferente e o ser deficitário, tem como conseqüência o aparecimento de condutas sociais novas (Ibãnez, 1998). Por parte de todos. Só assim o deficiente poderá se constituir em ser de direito. Um necessário começo para o resgate de nossa própria humanidade, sob pena de nos constituirmos - e aí, sim - como deficientemente humanos.

\section{Referências bibliográficas}

ASSMANN, Hugo. Reencantar a educação: rumo à sociedade aprendente. Petrópolis: Vozes, 1998.

CANGUILHEM, Georges. O normal e o patológico. 4. ed. Rio de Janeiro: Forense Universitária, 1995.

CORDIÉ, Anny. Atrasados não existem: psicanálise de crianças com fracasso escolar. Porto Alegre: Artes Médicas, 1996.

CROCHÍK, José L. Preconceito: indivíduo e cultura. São Paulo: Robe, 1995.

DEBRUN, Michel. A idéia de auto-organização. In: DEBRUN, M.; GONZALES, M. E. Q.; PESSOA JR., O. (Org.). Auto-organização: estudos interdisciplinares em filosofia, ciências naturais e humanas, e artes. Campinas: Unicamp, Centro de Lógica, Epistemologia e História da Ciência, 1996. v.18, p. 3-23. (Coleção CLE). 
DUPUY, Jean-Pierre. Nas origens das ciências cognitivas. São Paulo: Ed. da Universidade Estadual Paulista, 1996.

FOUCAULT, Michel. História da loucura na idade clássica. São Paulo: Perspectiva, 1978 ,

HEGEL, George W. F. Fenomenologia do espírito. Trad. de Paulo Meneses. Petrópolis: Vozes, 1992. v. 1.

IBÁÑEZ, Nolfa. Diversidad, ética e transformación social. In: CONGRESSO IBERO-AMERICANO DE EDUCAÇÃO ESPECIAL, 3. Atas... [S. 1.], 1998. p. 6-13.

MERLEAU-PONTY, Maurice. Fenomenologia da percepção. São Paulo: Martins Fontes, 1996.

VARELA, Francisco. J. et al. The embodied mind: cognitive science and human experience. Cambridge: MIT Press, 1996.

VAN GELDER, Tim. The dynamical hypothesis in cognitive science. Behavioral and brain sciences, n. 21. p. 615-628. (1998). Disponível em: $<$ http://www.arts.unimelb.edu.au/ tgelder/papers/DH.pdf> Acessado em: nov. 2004.

VAN GELDER, Tim.; PORT, Robert. F. Mind as motion: explorations in the dynamics of cognition. MA: Bradford Books/MIT Press, 1995.

RAMSEY, William. Connectionism: philosophical issues. In: WILSON, R.; KEIL, F. (Ed.). The MIT Encyclopedia of the Cognitive Sciences. Cambridge: MIT Press, 1999.

SCHWARTZ, Robert. Rationalism x empiricism. In: WILSON, R. A.; KEIL, F. (Ed.). The MIT Encyclopedia of Cognitive Sciences. Cambridge: MIT Press, 1999.

SMITH, B. Computation. In: WILSON, R.; KEIL, F. (Ed..) The MIT Encyclopedia of Cognitive Sciences. 1998. Disponível em: $<$ http://mitpress.mit.edu/MITECS/>

WILSON, Robert A. The Philosophy of Science: an encyclopedia. New York: Routledge Press, 2005.

YSSELDYKE, James; ALGOZINE, Bob; THURLOW, Martha. Critical issues in special education. Boston: Houghton Mifflin, 1992. 
Maria Luisa Bissoto é doutora em Educação pela Universidade Metodista de Piracicaba (Unimep). Suas atividades profissionais estão ligadas ao campo da reabilitação, da educação especial e da educação inclusiva. No ensino superior tem lecionado em cursos de especialização e de graduação em universidades do Estado São Paulo. Atua na área de educação, com ênfase em processos cognitivos e processos de ensino-aprendizagem.

malubissoto@yahoo.com.br

Recebido em 15 de dezembro de 2006.

Aprovado em 23 de abril de 2007. 